\title{
Comunicación
}

\section{Efectividad del tratamiento de mastocitoma cutáneo múltiple de alto grado usando un inhibidor de tirosina quinasa y vinblastina: reporte de caso}

\author{
Effectiveness of treatment of high-grade multiple cutaneous mast cell tumour \\ using tyrosine kinase inhibitor and vinblastine: case report \\ Paola C. Mujica ${ }^{1,4}$, Marcia Bustamante ${ }^{1}$, Lii Bascuñan², Vicente Sanhueza ${ }^{3}$
}

\section{Resumen}

El mastocitoma cutáneo es la neoplasia de piel más común en perros. Se presenta el caso de un paciente canino, de raza Shar Pei, hembra, de 10 años, que se presentó en consulta con múltiples masas eritematosas en la cara medial del miembro posterior derecho. Mediante examen citológico e histopatológico se diagnosticó mastocitoma de alto grado. La paciente fue tratada con omeprazol y con un protocolo de quimioterapia en base a una combinación vinblastina, prednisona y un inhibidor de tirosina quinasa. Durante el seguimiento mensual de la evolución de la paciente se observó remisión parcial de las masas que se mantuvo estable durante siete meses, momento en el cual se decidió suspender el uso de vinblastina. Luego de un mes de este cambio, no hubo recidiva de las masas previamente tratadas; sin embargo, se evidenció la aparición de nuevas neoplasias eritematosas y ulceradas en otra región del miembro posterior afecta-

\footnotetext{
${ }^{1}$ Núcleo de Investigación Aplicada en Ciencias Veterinarias y Agronómicas, Universidad de Las Américas, Santiago, Chile

${ }^{2}$ Clínica Veterinaria Pet's Life, Concón, Chile

${ }^{3}$ Neovet Centro de Especialidades Veterinarias, Viña del Mar, Chile

${ }^{4}$ E-mail: pmujica@udla.cl
}

Recibido: 4 de septiembre de 2019

Aceptado para publicación: 7 de agosto de 2021

Publicado: 27 de octubre de 2021

CLos autores. Este artículo es publicado por la Rev Inv Vet Perú de la Facultad de Medicina Veterinaria, Universidad Nacional Mayor de San Marcos. Este es un artículo de acceso abierto, distribuido bajo los términos de la licencia Creative Commons Atribución 4.0 Internacional (CC BY 4.0) [https://creativecommons.org/licenses/by/4.0/deed.es] que permite el uso, distribución y reproducción en cual-quier medio, siempre que la obra original sea debidamente citada de su fuente original 
do. Esta observación apoya la hipótesis de que la naturaleza genética de neoplasias del mismo tipo, en un mismo paciente, pudiese ser distinta y, por ende, determinar la respuesta al tratamiento y al pronóstico.

Palabras clave: mastocitoma de alto grado, tumores cutáneos, vinblastina, prednisona, inhibidor de tirosina quinasa

\section{AbSTRaCT}

Cutaneous mast cell tumour is the most common skin neoplasm in dogs. The case of a 10-year-old female Shar Pei canine patient is presented, who presented in consultation with multiple erythematous masses on the medial aspect of the right hind limb. By cytological and histopathological examination, high-grade mast cell tumour was diagnosed. The patient was treated with omeprazole and with a chemotherapy protocol based on a combination of vinblastine, prednisone, and a tyrosine kinase inhibitor. During the monthly follow-up of the evolution of the patient, partial remission of the masses was observed, which remained stable for seven months, at which time it was decided to suspend the use of vinblastine. After a month of this change, there was no recurrence of the previously treated masses; however, the appearance of new erythematous and ulcerated neoplasms in another region of the affected hind limb was evidenced. This observation supports the hypothesis that the genetic nature of neoplasms of the same type, in the same patient, could be different and, therefore, determine the response to treatment and prognosis.

Key words: high grade mast cell tumour, cutaneous tumour, vinblastine, prednisone, tyrosine kinase inhibitor

\section{INTRODUCCIÓN}

El mastocitoma cutáneo es el tumor cutáneo más frecuente en el canino, constituyendo alrededor del $20 \%$ de los tumores de piel en la especie (Villamil et al., 2011). Se observa predisposición racial, la cual puede correlacionarse también con el grado histológico en cada raza afectada. Por ejemplo, los perros Pug, Bulldog Francés y Bóxer tienen mayor riesgo de presentar mastocitomas de bajo grado, mientras que los Shar-Pei, Maltés y Weimaraner tienen mayor probabilidad de verse afectados por neoplasias de alto grado (Mochizuki et al., 2017; Smiech et al., 2017; Smiech et al., 2018; Reynolds et al., 2019).
Este tumor cutáneo, derivado de mastocitos de la dermis o del tejido subcutáneo, se caracteriza por tener una presentación clínica muy variable, lo que dificulta el pronóstico. Las lesiones tumorales pueden ser eritematosas, edematosas, de crecimiento rápido, ulceradas, con o sin lesiones satélites, así como generar una reacción inflamatoria local e incluso generar signos paraneoplásicos. Los perros afectados pueden presentar signología gastrointestinal, derivada de la naturaleza proinflamatoria de los componentes de los gránulos de este tipo de células mastocíticas (histamina, heparina, proteasas) (Blackwood et al., 2012). La determinación del grado histológico es importante para establecer el pronóstico clínico. En la clasificación histológica del mastocitoma cutáneo se 

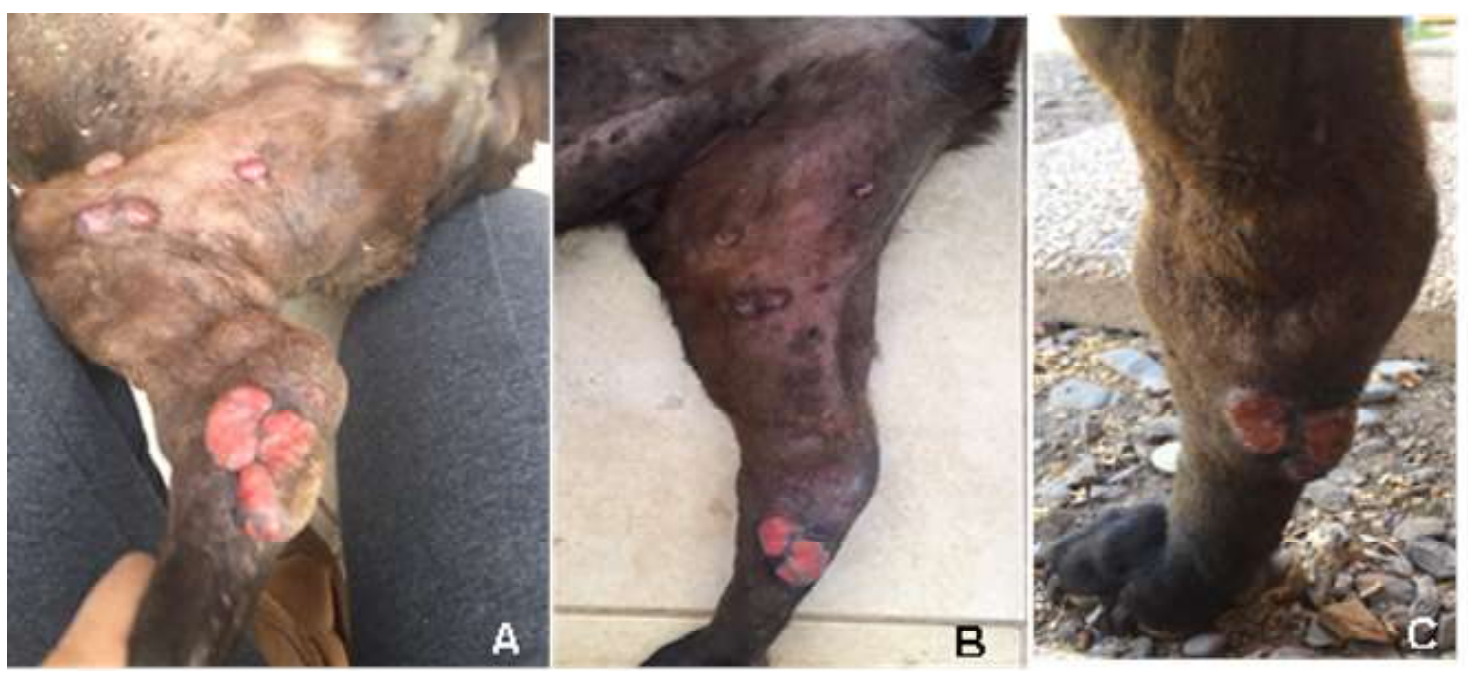

Figura 1. Imágenes de distribución y tamaño de las neoplasias (mastocitoma de alto grado citológico) en paciente canino Shar Pei, hembra de 10 años. A. Imagen registrada el día de la primera consulta. B. Imagen registrada 7 días postratamiento. C. Imagen del tumor de mayor tamaño registrada 10 días postratamiento

utiliza un sistema con tres grados histológicos (I, II y III) según Patnaik et al. (1984) y otro con dos categorías (bajo grado y alto grado) según Kiupel et al. (2011).

El curso y pronóstico de la enfermedad puede estar asociado a la presencia de mutaciones en el gen $c$-Kit. Este proto-oncogen codifica para una proteína de transmembrana que actúa como receptor de tirosina quinasa (Lennartsson et al., 2005). La mutación más frecuente del gen $c$-Kit es la duplicación del exón 11 , que causa una activación constitutiva del receptor, favoreciendo la activación de mecanismos celulares que favorecen la progresión del tumor (Blackwood et al., 2012). Ante esto, para el tratamiento del mastocitoma cutáneo, se han desarrollado fármacos que actúan como inhibidores de tirosina quinasa, tales como imatinib, toceranib y masitinib, siendo estos dos últimos tratamientos aprobados para su uso en medicina veterinaria (London et al., 2014). Imatinib en cambio, es un fármaco de uso humano, fue el primero en salir al mercado y su uso en el tratamiento de diferentes tipos de neoplasias está ampliamente validado (Waller, 2018). En perros, existen reportes del uso de imatinib en el tratamiento de mastocitomas cutáneos de alto grado con resultados que varían entre remisiones parciales, totales y tiempos de sobrevida de entre 20 y 47 semanas (Nakano et al., 2014; Kim et al., 2016).

Entre las drogas quimioterapéuticos más efectivas para el tratamiento del mastocitoma de alto grado se encuentran la vinblastina y la lomustina, que pueden ser utilizadas de manera individual o en combinación con prednisona (Blackwood et al., 2012). Se ha descrito un protocolo que combina vinblastina, prednisona y toceranib, el cual demostró tener eficacia y ser seguro en pacientes con tumores de alto grado (Olsen et al., 2018).

Se presenta un caso clínico de un mastocitoma cutáneo de alto grado en un canino de una de las razas más susceptibles a este tipo de tumor. Se estableció un tratamiento combinado que incorporó el uso de un 
fármaco inhibidor de tirosina quinasa, tratamiento poco difundido en Chile.

\section{Caso Clínico}

Se presenta en consulta privada un ejemplar canino, raza Shar Pei, hembra de 10 años, esterilizada, con vacunas al día y desparasitaciones pendientes. No convive con otros animales y reside, junto a sus propietarios, en la ciudad de San Antonio, Chile.

Al examen físico se observan masas múltiples y eritematosas, mayormente en la cara medial del miembro posterior derecho (Figura 1A). Según antecedentes de anamnesis, estas masas fueron identificadas por los propietarios un mes previo al día de la consulta. En el examen clínico se registró una frecuencia cardíaca de 130 latidos por minuto, frecuencia respiratoria de 20 por minuto, tiempo de llenado capilar de un segundo, mucosas rosadas e hidratadas, ausencia de secreciones nasales y oculares, abdomen normal a la palpación y temperatura rectal de $38.4{ }^{\circ} \mathrm{C}$.

En la consulta se procedió a realizar una citología mediante punción con aguja fina de las masas más representativas. A la muestra microscópica (Figura 2), se observó un componente celular moderado, compuesto por tres tipos celulares. El primer tipo fue de células caracterizadas por citoplasma y núcleo redondos, moderada relación núcleo/citoplasma, anisocitosis y anisocariosis marcada, frecuente macrocariosis, células en binucleación y escasa granulación; el segundo tipo celular presente fue de eosinófilos en moderada cantidad; y el tercer tipo fue de fibroblastos con características ocasionales de reactividad. Estas características fueron compatibles con mastocitoma de alto grado citológico.

Dado este resultado, se procedió a realizar la estadificación clínica de la paciente. En la radiografía de tórax no se observaron

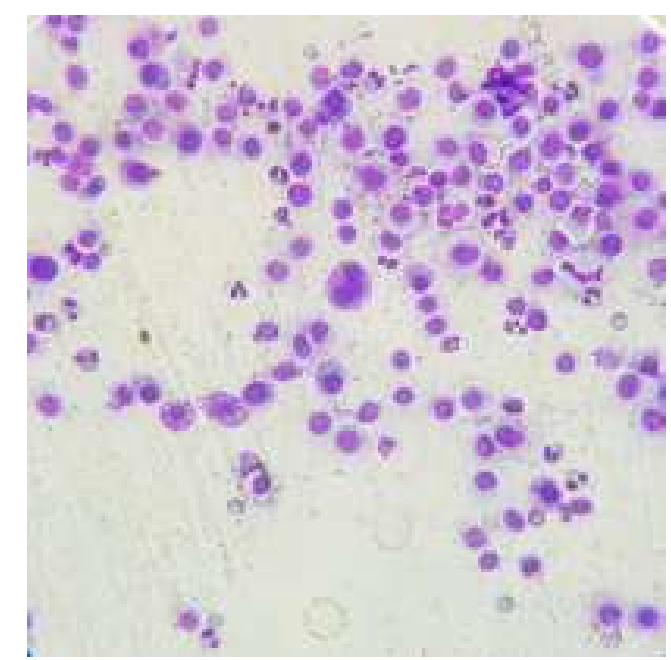

Figura 2. Imagen de citología obtenida mediante punción con aguja fina de una masa tumoral de mastocitoma de alto grado citológico. En el centro de la imagen se observa una célula multinucleada y abundantes mastocitos con escasos gránulos (Tinción Diff-Quik $^{\mathrm{TM}}, 40 \mathrm{X}$ )

anormalidades, a excepción de signos sugerentes de megaesófago. En la ecografía no se observaron anormalidades en los linfonodos mesentérico e iliácos y solo se informó como hallazgo una imagen sugerente de calcificaciones en el bazo. Dado que la paciente presentó al menos cuatro lesiones delimitadas, se clasificó a la neoplasia como un mastocitoma múltiple, sin evidencia de invasión de linfonodos ni de metástasis, lo que corresponde a estadio clínico II, según el sistema de clasificación propuesto por Horta et al. (2018). No se realizó punción con aguja fina de linfonodos regionales.

Para confirmar el diagnóstico sugerido por la citología, se obtuvo una muestra por biopsia excisional para estudio histopatológico. Se indicó Omeprazol oral en dosis de $0.5 \mathrm{mg} /$ $\mathrm{kg}$ cada 24 horas, para prevenir la manifestación de signos gastrointestinales. El informe histopatológico concluyó que el tipo celular predominante de la lesión fue de células mastocíticas, con marcada atipia celular, baja diferenciación, índice mitótico de 12 figuras en 10 campos de 400X, abundante vasculari- 


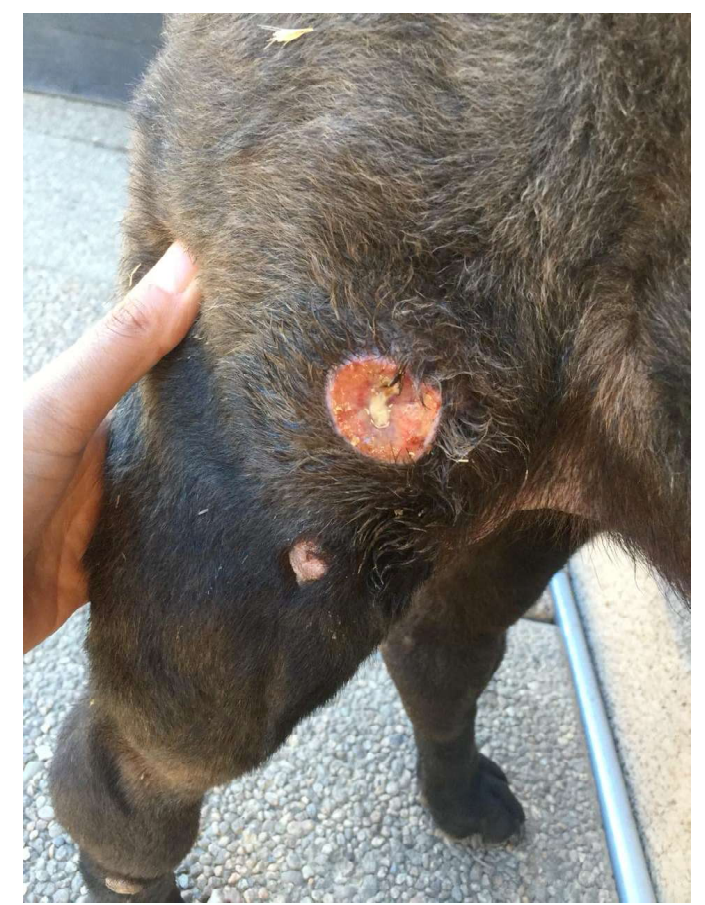

Figura 3: Imagen de neoplasias en perra Shar Pei de 10 años con mastocitoma de alto grado citológico, que se hicieron visibles luego de descontinuar el tratamiento con vinblastina

zación y necrosis amplia y diseminada en aproximadamente el $10 \%$ de la lesión, dando como diagnóstico mastocitoma de alto grado (Kiupel et al., 2011).

La paciente recibió tratamiento con una combinación de vinblastina, prednisona, e imatinib. El protocolo utilizado fue una variación del descrito por Olsen et al. (2018). Se indicó vinblastina $1.6 \mathrm{mg} / \mathrm{m}^{2}$ endovenoso cada 2 semanas, durante 16 semanas ( 8 dosis); imatinib $10 \mathrm{mg} / \mathrm{kg}$ vía oral diario durante 16 semanas; prednisona $1 \mathrm{mg} / \mathrm{kg}$ vía oral $1 \mathrm{vez}$ al día durante todo el proceso de tratamiento. En el periodo que la paciente estuvo en tratamiento, se realizaron controles mensuales durante siete meses, observándose remisión parcial de las masas tumorales, que se mantuvo estable desde el día 10 del tratamiento (Figuras 1B, 1C) hasta el séptimo mes.
A solicitud de la propietaria, se decide suspender el tratamiento de vinblastina al octavo mes, ya que este procedimiento resultaba muy estresante para el animal, exhibía evidentes señales de agresividad y requería de sedación para su manejo. El tratamiento continuó solo con imatinib y prednisona. Un mes posterior a este cambio, en la última consulta de seguimiento, no se observó recidiva de las masas tumorales que anteriormente habían experimentado remisión parcial, pero se evidenciaron dos nuevas masas ubicadas en la cara lateral del miembro anterior derecho, eritematosas y ulceradas (Figura 3 ). La citología de estas neoplasias resultó ser compatible con un mastocitoma de alto grado. Lamentablemente, la paciente falleció mientras dormía, tres semanas luego de la última consulta sin presentar ninguna signología paraneoplásica asociada a la presencia del mastocitoma cutáneo múltiple de alto grado.

\section{Discusión}

El mastocitoma cutáneo es la neoplasia que se diagnostica con mayor frecuencia en casos de neoplasias de piel en perros, por lo que existe un gran interés por investigar aspectos relacionados con la presentación, tratamiento y progresión de este tumor. Se conocen variantes genéticas que confieren riesgo de presentación de otras neoplasias menos frecuentes, como el sarcoma histiocítico en Boyero de Berna (Abadie et al., 2009; Shearin et al., 2012) y el melanoma en algunas razas de manto negro (Hernández et al., 2018); sin embargo, si bien se ha reportado una clara predisposición racial hacia la presentación de mastocitoma, se desconocen las mutaciones que pudiesen estar asociadas a mayor riesgo de desarrollo de esta neoplasia. Solo se ha determinado un polimorfismo genético en un gen que codifica para una proteína de adhesión celular, el cual estaría asociado a mayor riesgo de presentación de mastocitoma en las razas Golden Retriever y Labrador Retriever (Biasoli et al., 2019). 
Sería interesante conocer si estos polimorfismos también están presentes en otras razas que presentan mayor predisposición a este tipo de neoplasia, como los Shar Pei, ya que diferencias en las secuencias génicas entre razas pudiesen relacionarse con la alta variabilidad de presentación clínica de la enfermedad.

El pronóstico de vida en pacientes con mastocitoma cutáneo depende de múltiples factores, como el grado histológico, estadio clínico, localización de las masas, índice de proliferación, tasa de crecimiento, densidad de vascularización, recurrencia, presencia de signos sistémicos, edad, raza, sexo, tamaño del tumor y presencia de mutaciones en el gen $c$-Kit (Withrow et al., 2013). Entre estos factores, el grado histológico reviste de especial importancia. Independiente del sistema de clasificación histopatológica que se utilice (Patnaik o Kiupel), las neoplasias que contienen células más diferenciadas tienen mejor pronóstico que aquellas que exhiben alto grado de indiferenciación y características histológicas de malignidad, como marcada atipia celular y alta vascularización. Las primeras corresponden a un tipo de neoplasia más benigno, ya que menos del 10\% hace metástasis y generalmente no causa la muerte del paciente (Blackwood et al., 2012).

La sobrevida de los pacientes que presentan neoplasias de alto grado puede variar entre 70 y $>1000$ días, si se instaura un protocolo de tratamiento quirúrgico y adyuvante adecuado, que combine drogas anticancerígenas con distinto mecanismo de acción, tal como el protocolo usado en este caso clínico que incorporó vinblastina, prednisona y un inhibidor de tirosina quinasa, basándose en lo reportado por Olsen et al. (2018). Estos autores, a partir de un estudio retrospectivo evaluaron la progresión y sobrevida de pacientes de tres grupos, según factores pronósticos, reportando una respuesta positiva en el $90 \%$ de los pacientes, con tiempos de sobreviva variable. En el caso del presente reporte el tiempo de sobrevida de la paciente fue de 260 días (37 semanas), lo que con- cuerda con los resultados de sobrevida promedio del grupo que recibía tratamiento paliativo (218 días) en el estudio de Olsen et al. (2018).

La paciente no presentó evidencia de metástasis ni de signología paraneoplásica durante el periodo de seguimiento. No obstante, se observó una rápida progresión de la enfermedad luego de retirar la administración de vinblastina, evidenciándose nuevas masas que fueron compatibles con un mastocitoma escasamente diferenciado, a la vez que las masas que habían experimentado remisión parcial se mantuvieron estables. Este tipo de progresión agresiva en algunas masas y casi ausente en otras podría estar relacionada a la naturaleza biológica de cada una de las neoplasias de la misma paciente. Se ha observado que existen diversos tipos de mutaciones en el gen c-Kit, con distinta frecuencia en los casos de mastocitoma, pero que en su conjunto están presentes en el 30\% de los caninos afectados (Bonkobara et al., 2015). Además, existe evidencia de que los mastocitomas de alto grado pueden generar resistencia al tratamiento con inhibidores de tirosina quinasa en perros (Nakano et al., 2017), lo que sugiere que las células tumorales evolucionan generando mutaciones secundarias que les permiten mantener su alta proliferación. La mortalidad causada por la neoplasia ocurre en más del $80 \%$ de los casos y previo a los 175 días (Horta et al., 2018).

En el caso reportado, se observó recurrencia inmediata luego de la biopsia excisional que se realizó para confirmar el diagnóstico, por lo que se podría inferir que la potencial rápida progresión de estas masas fue inhibida con el tratamiento antineoplásico instaurado, permitiendo remisiones parciales que se mantuvieron estables durante 210 días en los que la paciente tuvo una buena calidad de vida. Al suprimir la administración de vinblastina, las neoplasias que habían experimentado remisión parcial no experimentaron recurrencia. Esto pudo deberse a que estos tumores tenían gran sensibilidad al inhibidor de tirosina quinasa; es decir, la remisión par- 
cial podría haber estado explicada por la acción de la combinación de imatinib y prednisona. Sin embargo, probablemente otros microtumores estaban siendo controlados con el tratamiento de vinblastina, los cuales se hicieron evidentes al poco tiempo de retirar la droga del protocolo de tratamiento.

Por lo tanto, existe una alta probabilidad de que las primeras masas de esta paciente hayan contenido mutaciones en $c$-Kit, pero no las nuevas neoplasias. Esto permitiría explicar la rápida progresión de la enfermedad a través de nuevas neoplasias, a pesar de la continuidad del tratamiento con imatinib. Este reporte de caso presenta evidencia sugerente que permite apoyar la existencia de tumores con características genéticas diferentes en un mismo paciente. Lamentablemente no fue posible realizar el diagnóstico de mutaciones en $c$-Kit en estos tumores, lo que hubiese permitido confirmar esta hipótesis (Thamm et al., 2019).

\section{Conclusiones}

La utilización del protocolo de quimioterapia combinada de vinblastina, prednisona e imatinib demostró buena tolerancia en la paciente, no generó neutropenia y favoreció el tratamiento del mastocitoma cutáneo mútiple de alto grado, aun cuando los factores predisponentes sugerían un pronóstico reservado y baja sobrevida.

\section{Literatura Citada}

1. Abadie J, Hédan B, Cadieu E, De Brito C, Devauchelle P, Bourgain C, Parker HG, et al. 2009. Epidemiology, pathology, and genetics of histiocytic sarcoma in the Bernese mountain dog breed. J Hered 100(Suppl 1): 19-27. doi: 10.1093/jhered/esp039
2. Biasoli D, Compston-Garnett L, Ricketts SL, Birand Z, Courtay-Cahen C, Fineberg E, Arendt M, et al. 2019. A synonymous germline variant in a gene encoding a cell adhesion molecule is associated with cutaneous mast cell tumour development in Labrador and Golden Retrievers. PLoS Genet 15(3): e1007967. doi: 10.1371/journal.pgen.1007967

3. Blackwood L, Murphy S, Buracco P, De Vos JP, De Fornel-Thibaud P, Hirschberger J, Kessler M, et al. 2012. European consensus document on mast cell tumours in dogs and cats. Vet Comp Oncol 10: e1-e29. doi: 10.1111/ j.1476-5829.2012.00341.x

4. Bonkobara M. 2015. Dysregulation of tyrosine kinases and use of imatinib in small animal practice. Vet J 205: 180188. doi: 10.1016/j.tvj1.2014.12.015

5. Hernández B, Adissu HA, Wei BR, Michael HT, Merlino G Simpson R. 2018. Naturally occurring canine melanoma as a predictive comparative oncology model for human mucosal and other triple wild-type melanomas. Int J Mol Sci 19: 394. doi: 10.3390/ijms19020394

6. Horta RS, Lavalle GE, Monteiro LN, Souza MC, Cassali GD, Araújo RB. 2018. Assessment of canine mast cell tumor mortality risk based on clinical, histologic, immunohistochemical, and molecular features. Vet Pathol 55: 212223. doi: $10.1177 / 0300985817747325$.

7. Kim JH, Kim HJ, Kim DH, Yim JH, Lee SJ, Park KH, Yoon HY. 2017. Successful response to imatinib in two dogs with inoperable grade III infiltrating mast cell tumours: a case report. Vet Med (Praha) 61: 467-473 doi: 10.17221/ 87/2016-VETMED

8. Kiupel M, Webster JD, Bailey KL, Best S, DeLay J, Detrisac CJ, Fitzgerald SD, et al. 2011. Proposal of a 2-tier histologic grading system for canine cutaneous mast cell tumors to 
more accurately predict biological behavior. Vet Pathol 48: 147-155. doi: 10.1177/0300985810386469

9. Lennartsson J, Jelacic T, Linnekin D, Shivakrupa R. 2005. Normal and oncogenic forms of the receptor tyrosine kinase kit. Stem Cells 23: 16-43. doi: 10.1634/stemcells.2004-0117

10. London CA. 2014. Small molecule inhibitors in veterinary oncology practice. Vet Clin North Am Small Anim Pract 44: 893-908. doi: 10.1016/j.cvsm.2014.06.001

11. Mochizuki H, Motsinger Reif A, Bettini C, Moroff S, Breen M. 2017. Association of breed and histopathological grade in canine mast cell tumours. Vet Comp Oncol 15: 829-839. doi: $10.1111 /$ vco. 12225 .

12. Nakano Y, Kobayashi T, Oshima F, Fukazawa E, Yamagami T, Shiraishi Y, Takanosu M. 2014. Imatinib responsiveness in canine mast cell tumors carrying novel mutations of c-KIT exon 11. J Vet Med Sci 76: 545-548. doi: 10.1292/jvms. 13-0156

13. Nakano Y, Kobayashi M, Bonkobara M, Takanosu M. 2017. Identification of a secondary mutation in the KIT kinase domain correlated with imatinibresistance in a canine mast cell tumor.Vet Immunol Immunopathol 188: 84-88. doi: 10.1016/j.vetimm.2017.05.004

14. Olsen JA, Thomson M, O'Connell K, Wyatt K. 2018. Combination vinblastine, prednisolone and toceranib phosphate for treatment of grade II and III mast cell tumours in dogs. Vet Med Sci 4: 237-251. doi: $10.1002 / \mathrm{vms} 3.106$

15. Patnaik AK, Ehler WJ, MacEwen EG. 1984. Canine cutaneous mast cell tumor: morphologic grading and survival time in 83 dogs. Vet Pathol 21: 469-474. doi: $10.1177 / 030098588402100503$

16. Reynolds BD, Thomson MJ, O'Connell K, Morgan EJ, Gummow B. 2019. Patient and tumour factors influencing canine mast cell tumour histological grade and mitotic index. Vet Comp Oncol 17: 338-344. doi: 10.1111/ vco. 12477

17. Shearin AL, Hedan B, Cadieu E, Erich SA, Schmidt EV, Faden DL, Cullen J, et al. 2012. The MTAPCDKN2A locus confers susceptibility to a naturally occurring canine cancer.Cancer Epidemiol Biomarkers Prev 21: 1019-1027. doi: 10.1158/1055-9965.EPI12-0190-T

18. Smiech A, Slaska B, Lopuszyñski W, Jasik A, Szczepanik M, Wilkolek $\boldsymbol{P}$. 2017. Epidemiological study of canine mast cell tumours according to the histological malignancy grade. Pol J Vet Sci 20: 455-465. doi: 10.1515/pjvs-20170055

19. Smiech A, Slaska B, Lopuszyñski W, Jasik A, Bochynska D, Dabrowski R. 2018. Epidemiological assessment of the risk of canine mast cell tumours based on the Kiupel two-grade malignancy classification. Acta Vet Scand 60: 70. doi: 10.1186/s13028-018-0424-2

20. Thamm DH, Avery AC, Berlato D, Bulman-Fleming J, Clifford CA, Hershey AE, Intile JL, et al. 2019. Prognostic and predictive significance of KIT protein expression and c-kit gene mutation in canine cutaneous mast cell tumours: a consensus of the OncologyPathology Working Group. Vet Comp Oncol 17: 451-455. doi: 10.1111/ vco. 12518

21. Villamil JA, Henry CJ, Bryan JN, Ellersieck M, Schultz L, Tyler JW, Hahn $\boldsymbol{A W}$. 2011. Identification of the most common cutaneous neoplasms in dogs and evaluation of breed and age distributions for selected neoplasms. J Am Vet Med Assoc 239: 960-965. doi: 10.2460/javma.239.7.960

22. Waller CF. 2018. Imatinib mesylate. Recent results. Cancer Res 212: 1-27. doi: 10.1007/978-3-319-91439-8_1

23. Withrow SJ, Page R, Vail DM, Rodney L. 2013. Withrow and MacEwen's small animal clinical oncology. Saunders. 750 p. 